\title{
CONSTRUINDO UM ESPAÇO DE REFLEXÕES E POSSIBILIDADES DO BUDISMO NAS PRÁTICAS CURRICULRARES DO ENSINO RELIGIOSO
}

\author{
Building space for reflections and possibilities of Buddhism in the practices of \\ the religious education curriculum
}

REIS, Marcos Vinicius Freitas ${ }^{1}$ UFAP - Amapá / Brasil

SANTOS, Mirinalda Alves Rodrigues dos UFPB - Paraíba /Brasil ${ }^{2}$

\begin{abstract}
RESUMO: Este artigo insere-se no campo das discussões sobre o Budismo no Ensino Religioso, bem como a dificuldade dessa religião e/ou filosofia de vida ser incorporado nas práticas curriculares desse ensino, devido a um cenário de preconceitos e discriminações diante de alguns determinados grupos cujas suas crenças religiosas não são consideradas das religiões ocidentais. Nesse sentido, o Ensino Religioso passa ser um componente importante para romper práticas repressoras no que envolve às diversas manifestações culturais religiosas, inclusive quando nos direcionamos para as religiões orientais. Nessa perspectiva, o estudo aqui proposto é construído com o objetivo de contribuir para a inserção do Budismo de forma reflexiva, crítica, não confessional nas práticas curriculares do Ensino Religioso, na perspectiva do combate da intolerância religiosa nas escolas. Metodologicamente essa pesquisa é qualitativa com coleta de dados empíricos através de entrevista semi-estruturadas realizadas com alguns docentes atuantes no Ensino Religioso, no entanto, identificamos que há uma lacuna no que diz respeito à formação inicial e continuada dos docentes para abordar de forma consistente o Budismo em sala de aula, diante disso, apresentaremos por fim, uma possibilidade de práticas pedagógicas a partir de temas norteadores e objetivos propostos de como trabalhar o universo budista no componente curricular Ensino Religioso.

Palavras-chave: Ensino Religioso; Budismo; Práticas curriculares.
\end{abstract}

ABSTRACT: This article inserts itself in the field of discussions about Buddhism in Religious Education, as well as the difficulty of this religion and/or philosophy of life to be embedded in the curricular practices of this teaching, due to a backdrop of prejudice and discrimination facing certain groups whose religious beliefs are not considered to be of western religions. $\mathrm{n}$ this sense, the Religious Teaching is to be an important component to break practices repressive in that it involves the diverse cultural manifestations of religious beliefs, even when we turn to the eastern religions. In this perspective, the study proposed here is constructed with the aim of contributing to the insertion of the Buddhism of shape reflective, critical, non-confessional practices of the curriculum of Religious Education, in the perspective of the combat of religious intolerance in schools. Methodologically this research is qualitative with the collection of empirical data through semi-structured conducted with some teachers who are active in Religious Education, however, we have identified that there is a gap in respect to the initial and continuing training of teachers to address consistently the Buddhism in the classroom, on the face of it, we finally, a possibility of pedagogical practices from themes guiding and goals of how to work the buddhist universe, on the component of the curriculum Religious Education.

Keywords: Religious Education; Buddhism; Curriculum practice.

1 Doutor em Sociologia/UFSCar. Docente do Programa de Pós-Graduação Profissional em Ensino de História/UNIFAP e do Curso de Especialização em Estudos Culturais e Políticas Públicas/UNIFAP. Professor do Curso de Relações Internacionais/UNIFAP. Coordenador do Grupo Centro de Estudos Políticos, Religião e Sociedade (CEPRES). E-mail: marcosvinicius5 @yahoo.com.br

${ }^{2}$ Doutoranda e Mestra em Ciências da Religião pela Universidade Federal da Paraíba PPGCR/ UFPB. E-mail: mirirodrigues2@gmail.com. 


\section{Introdução}

Atualmente as discussões acerca da inserção das religiões consideradas não cristãs estão cada vez mais frequentes e ganhando força nos fóruns e nas políticas educacionais acerca do Ensino Religioso, inclusive devido o reconhecimento desse ensino como componente curricular na área das Ciências Humanas na Base Nacional Comum Curricular - BNCC. Considerando, assim, como temas emergentes que devem ser contempladas nas práticas curriculares $^{3}$ desse ensino. Com um debate que esse componente curricular deve possibilitar o reconhecimento e compreensão das pluralidades de manifestações religiosas que temos no mundo multicultural, objetivando que todos os alunos conheçam as dimensões históricas, sociais, diante da diversidade cultural religiosa.

É nesse contexto que se se insere as religiões orientais que, ao longo do tempo, são negadas na sociedade ocidental por sua cultura, por suas práticas, por suas crenças e por suas manifestações religiosas, diferentes das religiões que sobrepõem na cultura ocidental, que são as religiões cristãs. Gerando assim, intolerância religiosa acerca do Budismo nas escolas. E essas negações acabam influenciando nos processos de ensino e aprendizagem que envolve as práticas curriculares do Ensino Religioso. Assim, construindo dogmas, preceitos e uma visão restrita do que vem a serem as religiões orientais perpetuadas nas ações pedagógicas, inclusive por parte dos professores, devido à falta de formação inicial continuada que permite a não compreensão, o não conhecimento mais amplo e crítico acerca dessas religiões.

É nessa perspectiva que esse estudo busca contribuir para (re)pensar e (des)construir essa má interpretação e visão de que não é impossível/difícil de serem pensados ao elaborarem o planejamento de aulas, de atividades e de materiais didáticopedagógicos que possam contribuir na formação histórica, política, social dos alunos e desenvolver princípios éticos, respeito, valores e a cultura de paz baseada na convivência pacífica diante da diversidade cultural religiosa. Nesse sentido, tomamos como objeto de estudo, o Budismo.

\footnotetext{
${ }^{3}$ De acordo com Amorim e Neto (2012, p. 332), "Entendemos como práticas curriculares todo exercício característico da escola na organização e no desenvolvimento do currículo, ou seja, dos conteúdos e formas de sua transmissão e tarefas propostas, bem como acompanhamento dos estudantes no processo de ensino e aprendizagem. Dizendo de outra forma, as práticas curriculares são entendidas como conjunto de ações levadas a cabo para a constituição do que chamamos de currículo escolar".
}

REVISTA RELEGENS THRÉSKEIA - 2018 - UFPR - UEPA 
A relevância dessa pesquisa se dá devido à falta de referências intelectuais que temos em trazer a discussão do Budismo nas práticas curriculares do Ensino Religioso. Com uma discussão teórica e didática pedagógica, o referido estudo destina-se aos professores desse ensino para uma maior compreensão e auxílio no desenvolvimento das ações pedagógicas do componente curricular Ensino Religioso.

Metodologicamente essa pesquisa é qualitativa e está dividida em três tópicos. $\mathrm{O}$ primeiro tópico corresponde às reflexões teóricas acerca do Budismo de forma que possamos compreender a importância dessa religião enquanto filosofia, prática analítica na ótica budista, trazendo a discussão para uma abordagem no Ensino Religioso. O segundo tópico diz respeito às análises das entrevistas que foram feitas através de um questionário com professores que atuam/atuaram no componente curricular Ensino Religioso. Com o intuito de entender como eles compreendem e como desenvolvem ou não, as atividades pedagógicas acerca do Budismo. E, por fim, o último tópico traz uma abordagem de possibilidades de como o Budismo pode ser desenvolvido e aplicado nas práticas curriculares do Ensino Religioso a partir do que chamamos de temas norteadores, bem como os objetivos a quem eles se relacionam.

\section{Budismo e Ensino Religioso: desafios nas práticas curriculares}

O desafio de discutir o Budismo no Ensino Religioso refere-se às tendências das práticas curriculares desse ensino em preconizar as religiões ocidentais, ora acreditamos que essa questão de preterir as religiões orientais seja pela falta da formação (inicial e continuada). E isso contribui para concepções que são postas ao senso comum no currículo do Ensino Religioso e que são reproduzidas nas ações pedagógicas, metodológicas e avaliativas em diversas situações como: nos Projetos Políticos Pedagógicos, nos livros didáticos, nos planejamentos, nos planos de aula, entre outras diversas práticas curriculares.

Essa visão nos permite a tentativa do debate de superação desses limites no Ensino Religioso, a partir dos estudos pós - críticos ${ }^{4}$ de currículo que nos leva a ter uma concepção híbrida, dinâmica, ampliada e modificada dos discursos hegemônicos, construindo a valorização das diversas manifestações culturais advindos do

\footnotetext{
${ }^{4} \mathrm{Na}$ perspectiva do currículo pós-crítico, podemos entender a importância que se dá na valorização das identidades e diferenças no multiculturalismo, conforme Silva (2007, p. 86), o currículo pós-crítico não é "uma hierarquia entre as culturas".
} 
multiculturalismo, conforme Oliveira (2015, p. 25), "o multiculturalismo reconhece a busca pelo reconhecimento que coincide com a história das demandas por inclusão e pelos direitos e reconhecimento de grupos específicos que foram invisibilizados ao longo dos séculos, em nossas sociedades".

Assim, é preciso que o currículo multicultural do Ensino religioso suprassuma as barreiras e possibilite a compreensão das tradições culturais religiosas, nas quais vivem de múltiplas formas, porém que se interagem umas com as outras de forma direta e/ou indireta. Entre essas tradições religiosas destacamos o Budismo que teve origem por volta do século VI a.C. A difusão do Budismo se deu a partir de Sidarta Gautama ${ }^{5}$ que ficou conhecido como o (Buda), segundo Rinpoche (2012, p. 23), “A palavra buda tem dois significados: $\mathrm{O}$ primeiro refere-se à essência da mente, que é e sempre foi a verdadeira natureza de todos os seres. O segundo significado se refere a quem revelou completamente a natureza búdica”. Dessa forma, podemos entender que a palavra é um título que foi atribuído por ele ter despertado da ignorância e alcançou a iluminação.

O Budismo é uma religião não - teísta (que não tem um Deus e/ou deuses como uma divindade centralizadora como estamos acostumados de ver nas demais religiões, principalmente nas ocidentais). No entanto, o Budismo, é considerado como uma filosofia de vida, ou seja, uma prática que trabalha com a mente a partir dos estágios de superação dela mesma. Smith (2006, p. 79) afirma que "[...] "Budismo", no inglês como em outras línguas ocidentais, designava mais ou menos desde o início um desenvolvimento histórico, um complexo em evolução de crenças, práticas, instituições e dados observáveis." O fato é conceituar o Budismo é algo complexo por ser um universo amplo e inimaginável para algumas pessoas.

Partindo dessa concepção podemos compreender o Budismo, enquanto uma estrutura de pensar filosoficamente e diante dos ensinamentos budistas que nos leva a despertar para a verdade, isto é, entender a verdade como ela é, sem ter os fatores ilusórios condicionados diante do mundo formado por sentimentos (de raiva, de ignorância, de ganância, etc.). Um dos objetivos principais do Budismo é o fato de termos a capacidade de analisar a forma de como percebemos o mundo, a partir da concepção consciente da mente no que se refere ao nosso próprio ser e, a partir disso,

\footnotetext{
${ }^{5}$ Filho do rei Shakya e a rainha Mayadevi, Sidarta Guatama nasceu por volta de dois mil e quinhentos anos na divisa do Nepal com a índia. Rinpoche (2012).
} 
termos o domínio das emoções que nos causam sofrimento ${ }^{6}$.

Nesse sentido, um dos elementos importantes considerado nos ensinamentos budistas de acordo com As Quatro Nobres Verdades diz respeito à cessação do sofrimento, uma vez que é condicionado pela percepção e pela compreensão dialética da causa e do efeito diante das aversões opostas de sentimentos e emoções que nos impede do contínuo ciclo de renascimento (Samsara), ${ }^{7}$ o que causa assim, o sofrimento. Entretanto, sabemos que essa compreensão não é fácil e é claro que não é de uma hora para outra que teremos o discernimento da libertação do sofrimento. Para isso, agir de forma que esses sentimentos não dominem a nossa mente e não nos impulsionem a uma prática de comportamentos despreciáveis causados pelas emoções não autorreferentes. De acordo com Bhikkhu, (2013, p.174):

\begin{abstract}
A meta dos ensinamentos budhistas está em nos instruir sobre a inexistência do eu permanente e de qualquer coisa que permaneça ao eu; existe somente o falso entendimento da mente ignorante. Existe apenas o corpo e a mente que nada mais são que simples processos naturais. Eles funcionam como um mecanismo que processa e transforma dados. Se eles fazem isso pelo método errado, o resultado é tolice e ilusão, de tal forma que a pessoa sente que existe um eu permanente e coisas que pertencem a ele. Se o fazem pelo método correto, esses sentimentos não aparecem, mas sim a consciência primária que discerne a verdade (satipañña), o saber verdadeiro fundamental e a visão clara de que não existe o eu permanente nem qualquer coisa que pertença a ele.
\end{abstract}

Assim, a compreensão do sofrimento que "se deve a negatividade da mente que nos induz a fala e a atos prejudiciais" (RINPOCHE, 2012, p. 30), gera assim, karmas negativos e que nos permite olhar para o interior de uma concepção da vida mentalespiritual e para a busca da cessação do mesmo, temos o primeiro ensinamento do Buda conhecidos como: As Quatro Nobres Verdades, essas por sua vez, são meios para o alcance da paz e liberdade transcendental de forma analítica. As Quatro Nobres Verdades são: 1. Verdade do sofrimento; 2. Verdade da origem do sofrimento; 3. Verdade da cessação do sofrimento; 4. Verdade do caminho que leva à cessação do sofrimento. Segundo Dhammasami (2013, p. 51)

Se você considerar 1 e 2 como o lado escuro da vida, então 3 e 4 podem ser considerados como a parte luminosa da vida. Se você falar apenas sobre o lado luminoso e não do lado escuro, então não poderá ser uma verdade ou

\footnotetext{
${ }^{6}$ Sofrimento (Dukkha). SASAKI, (2013).

${ }^{7}$ Fluxo de renascimentos incessante em uma perpétua repetição cíclica do nascimento e da morte (Samsara). Ibidem5.
}

REVISTA RELEgENS THRÉSKEIA - 2018 - UFPR - UEPA 
saccā. Não seria completo apenas falar sobre as causas das coisas ruins e não mencionar nada sobre como superá-las, Neste sermão está tudo lá. É completo. Qual o problema? Édukkha. Como é causado? Há um fim para o dukkha e como se conseguir isso? Tudo isso é explicado no sermão.

Toda a prática do Bhuddismo está incluída neste sermão, nas Quatro Nobres Verdades. 1 e 2 estão relacionado como causa e efeito, mas 3 e 4 não. Se você pensar bem, você vai entender que praticando o 4 , ou trilhando o caminho, praticando o caminho óctuplo ${ }^{8}$, isto conduz à cessação do dukkha. Assim o número 4 é meramente um caminho a ser seguido.

Nesse sentido, a última Nobre Verdade, podemos assim dizer que é uma sabedoria profunda da vida e da existência de forma que possamos ser conduzidos à cessação do sofrimento e da aquisição da paz interior. Esse processo é conhecido como o Caminho do Meio e é um dos principais ensinamentos do Buda. O Caminho do Meio, diz respeito ao descobrimento pelas suas próprias existências, assim possibilitando o discernimento e a sabedoria que temos em andar sempre em equilíbrio, com a vida material a nossa vida espiritual, isto é, saber afastar do extremismo tanto da autoindulgência quanto da automortificação. Com essas concepções e ensinamentos, o Budismo foi ramificando ao longo dos séculos e adquirindo divisão dos praticantes budistas na Índia após a morte do Buda em meios às divergências acerca da sua doutrina.

A partir dessas divisões surgem as escolas budistas, entre elas, podemos citar: A Theravada - Considerada a escola mais antiga, sendo o primeiro grupo dessa divisão; a Mahayana - Tem como fundador dessa escola o Nagarjuna ${ }^{9}$, que é reconhecido pelos Mahayanistas, sendo superado somente por Buda no tocante à importância e à profundidade de percepção. Nos seus escritos e ensinamentos destaca-se Mulamadhyamakakarika (Sabedoria fundamental do caminho do meio), aqui traz a concepção filosófica de que não é possível afirmar nada definitivamente acerca da realidade última do mundo. Gelug-pa- Conforme Silva e Homenko, (1998, p.192) “Gelug-pa (Os virtuosos); reorganizou o regime monástico, submetendo os monges ao

\footnotetext{
${ }^{8}$ Podemos assim dizer que é um caminho de virtude (sila), de treinamento mental (samadhi) e de sabedoria (pañña). A Virtude nesse sentido é indicada pela linguagem correta, ação correta e modo de vida correto. O Treinamento mental é indicado pelo esforço correto, atenção plena correta e concentração correta. A sabedoria é indicada pelo entendimento correto e pensamento correto. Assim, este libertador Caminho Óctuplo é um caminho de cultura interior, de progresso interior.

ver em THERA, Nyanatiloka. A essência do Budismo. Revisado: 2 de junho, 2012. Disponível em: <http://www.acessoaoinsight.net/arquivo_textos_theravada/essencia.php> Acesso em 10 de janeiro de 2017.

${ }^{9}$ Para obter mais compreensão acerca de Nagarjuna indicamos: ARNAU. Juan. La palavra frente al vacío. Filosofia de Nāgārjuna. México: Fondo de Cultura Ecomoníca, 2005.
}

REVISTA RELEGENS THRÉSKEIA - 2018 - UFPR - UEPA 
regime alimentar e ao celibato. Foi o renascimento do Budismo no Tibete e, outra vez, o Dharma voltou a brilhar como o "Sol entre as nuvens"'”. Essas escolas Budistas são importantes para a difusão dos ensinamentos budistas apesar das diferentes doutrinas e práticas especificas de cada uma, porém suas bases das tradições e práticas são do

\title{
Buddha-Dharma.
}

Essa breve introdução sobre o Budismo norteia o leitor (pesquisadores, professores e estudiosos do Ensino Religioso) a se familiarizar com o universo budista, tendo o intuito de apresentar elementos básicos para subsidiar o fazer pedagógico e de todo o conjunto de práticas de constituição do currículo escolar que aqui chamamos de práticas curriculares desse ensino. Para tanto, entendemos que o Budismo não é algo inalcançável de ser compreendido nem difícil de ser ensinado, é preciso que possamos incorporá-lo de forma clara e certa no currículo do ER como uma religião que historicamente e culturalmente nos apresenta na sua manifestação religiosa, no que diz respeito, às identidades, às tradições, às místicas, os mitos, os ritos e as espiritualidades. E isso é que o torna importante e que deve ser contemplado e contextualizado nas práticas curriculares do ER. De acordo com Oliveira, Junqueira, Alves e Keim (2007, p. 36-37),

\begin{abstract}
A pertinência e a relevância desse componente curricular encontram suporte no testemunho de diferentes pesquisadores e estudiosos que percebem na religiosidade uma porta para a compreensão de parte da natureza humana. A busca do ser humano de relacionamentos com o sagrado pode ser constatadas nos inúmeros elementos culturais, como festividades, edificações, textos e monumentos, entre outros, que se manifestam como referenciais de fé presentes no mundo.
\end{abstract}

Diante desse entendimento, remetemo-nos como as práticas curriculares escolares do Ensino Religioso estão compreendendo, contextualizando e problematizando o Budismo enquanto abordagem religiosa e espiritual que tem significação de reflexão na perspectiva budista de como vê a realidade de como se constrói e de como ele se relaciona com o mundo. Rinpoche (2012) defende que temos a visão de que o Budismo é complicado, difícil de entender por ter muitos métodos para serem apreendidos e pensados, porém existem razões para a existência desses vários métodos. Para tanto, a grande dificuldade nessa compreensão se dá pelo fato de equilibrar os sentimentos diante de um mundo atual em que prioriza mais o material do que o espiritual. 
Dessa forma, faz-se necessário a amplitude de conhecimento por parte dos professores acerca desse universo para poder construir de forma consciente e desmistificar e (des) construir imagens negativas/ errôneas que a cultura ocidental nos impôs. Diante dessas diferenças culturais, o currículo escolar destinado ao Ensino Religioso deve trazer as discussões de "uma identidade cultural particular que implica o reconhecimento de outras identidades" (MACEDO, 2006, p. 293). É nessa perspectiva que esse estudo no próximo tópico irá se debruçar a partir dos discursos produzidos por professores de Ensino Religioso acerca do entendimento e da prática no processo de ensino aprendizagem desenvolvidos com os alunos sobre o Budismo.

\section{Budismo: concepções e reflexões das atividades pedagógicas no Ensino Religioso}

Esse tópico destina-se às análises da aplicação de um questionário com perguntas abertas, que possibilitam a interrelação com os objetivos propostos nessa pesquisa no intuito de perceber as concepções dos professores de Ensino Religioso acerca do universo budista, as perguntas elaboradas no questionário foram pensadas de forma que os sujeitos da pesquisa pudessem refletir criticamente sobre o assunto abordado, uma vez que, estrategicamente nos facilite e corrobore para a compreensão, a delimitação e a relevância a partir das informações fornecidas pelos sujeitos submetidos nessa pesquisa, eis o que entendemos por questionário, de acordo com Moresi (2003. p. 30):

Questionário: é uma série ordenada de perguntas que devem ser respondidas por escrito pelo informante. $\mathrm{O}$ questionário deve ser objetivo, limitado em extensão e estar acompanhado de instruções As instruções devem esclarecer o propósito de sua aplicação, ressaltar a importância da colaboração do informante e facilitar o preenchimento.

É nessa perspectiva que destinamos o tópico desse artigo para a análise da aplicação do questionário que foi realizado com professores que lecionam ou lecionaram o componente curricular Ensino Religioso. A escolha dos sujeitos se deu a partir do fácil acesso de comunicação da autora com os mesmos. Foi aplicado o questionário com 06 (seis) professores, porém apenas 03 (três) responderam.

Nesse caso, o questionário tinha 05 (cinco) perguntas, em que as 2 (duas) primeiras eram mais de caráter identitários e as 3 (três) últimas perguntas eram de 
caráter subjetivas, no qual

o pesquisado poderiam responder embasada na vivência/experiência como professores de Ensino Religioso.

Primeiramente antes de fazermos as análises acreditamos que é importante apresentar o perfil dos sujeitos da pesquisa, uma vez que nos possibilita na percepção, na compreensão e na possível visualização de quem são esses sujeitos, optando aqui fazer um quadro sistemático de cada professor. Para a preservação da identidade desses sujeitos chamaremos, respectivamente, P (1), P (2) e P (3). Como podemos observar no quadro abaixo:

\begin{tabular}{|c|c|c|c|}
\hline Professor & $\begin{array}{l}\text { Anos de atuação } \\
\text { como professor de } \\
\text { Ensino Religioso }\end{array}$ & Sexo & Formação \\
\hline $\mathrm{P}(1)$ & 13 anos & Masculino & $\begin{array}{l}\text { Licenciado em } \\
\text { Letras e } \\
\text { mestrando em } \\
\text { Ciências das } \\
\text { Religiões- } \\
\text { UFPB } \\
\end{array}$ \\
\hline $\mathrm{P}(2)$ & $\begin{array}{l}2 \text { anos. Mas } \\
\text { atualmente não leciona }\end{array}$ & Masculino & $\begin{array}{l}\text { Licenciado em } \\
\text { História e } \\
\text { Ciências das } \\
\text { Religiões - } \\
\text { UFPB }\end{array}$ \\
\hline $\mathrm{P}(3)$ & 3 anos & Feminino & $\begin{array}{l}\text { Pedagoga e } \\
\text { Mestra em } \\
\text { Ciências das } \\
\text { Religiões- } \\
\text { UFPB }\end{array}$ \\
\hline
\end{tabular}

Quadro 01: Perfil dos entrevistados Fonte: Quadro organizado pelos autores.

Após a exposição do perfil dos professores de Ensino Religioso nos remetemos agora as análises realizadas diante das respostas do questionário aplicado. Aqui destacamos o cerne das questões que são precisamente as perguntas 3 (três), 4 (quatro) e 5 (cinco). Essas perguntas foram elaboradas de forma crítica que possibilitou o sujeito pesquisado a pensar acerca da sua visão, das suas ações pedagógicas, nos currículos e no processo de ensino e aprendizagem diante de uma temática relevante e que precisa um olhar mais crítico, no que diz respeito às práticas curriculares ao abordarem o Budismo. Nessas perspectivas foram feitas as seguintes perguntas: 
Na sua concepção, o que você entende sobre o Budismo?

A resposta do P (1) foi: "É uma religião que tem como chefe espiritual o Buda". Já o P (2) disse que: "Levando em consideração a amplitude do tema BUDISMO, considero meus conhecimentos bem limitados apenas a parte historiográfica”. E para $\mathrm{P}$ (3): "É uma linha religiosa com perspectiva filosófica com bases orientais de vasta cultura e tradições as quais busca a evolução espiritual de cada um".

Ao observarmos as respostas podemos perceber que há uma limitação na formulação do conceito e da concepção acerca do Budismo, a partir das respostas do P (1) e o P (2) que expressam claramente a sua limitação em "defini-lo". Já a P (3) apresenta ter a concepção um pouco mais aproximada do que vem a ser Budismo. O que podemos levar em consideração é o fato que essa limitação se dá através da lacuna na formação inicial e/ou continuada desses professores de Ensino Religioso. Uma vez que, ao observarmos o perfil dos mesmos, identificamos que os professores são vinculados ao curso de Ciências das Religiões - UFPB seja na licenciatura, ou seja, na Pósgraduação.

Como vimos no quadro acima o perfil desses professores são: o P (1) está cursando o mestrado, o P (2) é graduado no curso, e a P (3) é mestra nesse curso. Contudo, apesar dessa formação entendemos o problema não está apenas na formação, mas também na falta de interesse dos alunos em querer aprofundar os conhecimentos sobre essa temática por vários motivos que impulsionam aos preconceitos impostos socialmente, historicamente e culturalmente sobre religiões que não são consideradas cristãs e essas concepções são perpetuadas de forma direta e indireta nas escolas e no fazer pedagógico dos professores de ER. De acordo com Andrade (2013, p. 13), a Religião:

[...] normalmente atua a partir de alguma forma de organização e de culto, bem como por meio de ritos sagrados ou rituais, livros sagrados, um clero ou sacerdócio que administra a religião e lugares, símbolos, e os dias que são sagrados para os crentes. Por serem organizações instituídas, compartilham certas características comuns. estas incluem, mas não estão limitadas a: tradição e manutenção do sistema de crenças; utilização do mito e do símbolo; um conceito de salvação; lugares e objetos sagrados; a ações sagradas ou rituais; escrituras sagradas, locais de culto, experiências sagradas; códigos de comportamento ético; um corpo de especialistas que atendem as necessidades de seus grupo. 
Se adentrarmos no universo budista iremos verificar que possuem alguns desses elementos que caracterizam uma religião, entretanto, é preciso que o professor de Ensino Religioso busque meios de ampliar essa visão e quebrar certos preceitos estabelecidos ao longo do tempo, tomando como perspectiva que "o Ensino Religioso trabalha com conteúdos da dimensão mais profunda do ser humano - a espiritualidade e a relação de transcendência" (NASSER, 2013, p. 26). É nesse sentido que se faz necessário o professor desse componente curricular buscar elementos que dê subsídios a ampliação acerca dos conhecimentos em relação às religiões, no qual não tem domínio nos aspectos fenomenológicos de cada uma, em especial, o Budismo. Partimos agora para a quarta pergunta:

4. Em sua experiência como professor/a de Ensino Religioso você já trabalhou o Budismo em sala de aula? E de que forma foi trabalhado?

Para o P (1) "Sim, de forma muito superficial, ou seja, só a definição do budismo e falar que o chefe da religião é o Buda. Nada com profundidade do tema da aula. Simplesmente leitura informal pelo fato de não ter conhecimento sobre o Budismo". Para o P (2) "Durante o período em que estive como professor de ER em decorrência do pouco conhecimento sobre o que poderíamos chamar de ESSÊNCIA DO BUDISMO, trabalhei apenas a parte histórica" e para a P (3) "quando regente de sala nunca trabalhei e confesso que na época não tinha conhecimento especifico"

Observamos que nas falas desses professores reforçam o que já tinham elencados a respeito da falta de conhecimentos devido à falta de formação adequada nessa temática. É importante destacarmos que esse reconhecimento por parte dos professores é o primeiro passo do querer fazer diferente e compreender que o Budismo precisa ser mais expandido para a reafirmação do pluralismo religioso nas práticas educacionais do Ensino Religioso. Para Oliveira (2015, p. 79) o pluralismo religioso "chama a atenção para os aspectos da multiplicidade, da diversidade e da validade das experiências religiosas de outros povos e culturas". Assim entendemos que o Ensino Religioso é a interação e apreensão de múltiplas culturas. Na quinta e última questão foi elaborada da seguinte forma:

5. Na sua ótica você acha importante trabalhar o Budismo no componente curricular de Ensino Religioso? E de que forma o Budismo pode contribuir na formação dos educandos?

A resposta do $\mathrm{P}$ (1) foi:

REVISTA RELEgENS THRÉSKEIA - 2018 - UFPR - UEPA 
Falar sobre o Budismo na aula de ensino religioso é muito importante, uma vez que faz parte da grade curricular dos conteúdos. Faz-se necessário falar sobre as diversas religiões e o fenômeno religioso presentes nas mesmas. Uma das contribuições para a formação dos educandos é no sentido espiritual, ou seja, a meditação presente no ritual do budismo. Podemos citar no campo social quando se trata dos assuntos: ética, respeito e alteridade.

Segundo o P (2) "Não apenas o budismo. Considero que qualquer forma de conhecimento seja válida para o Ensino Religioso" e conforme a P (3) "Acredito que sim. As religiões orientais vêm crescendo bastante em nosso país. E a ignorância leva a intolerância, por isso conhecer as culturas religiosas contribuem pra a valorização da diversidade e a cultura de paz. Sem falar dos muitos saberes que a cultura oriental nos propicia.

O que podemos elencar nas respostas obtidas nessa última pergunta é que todos os professores têm a percepção da importância do Budismo ser contemplado nas práticas curriculares do Ensino Religioso destacando as seguintes perspectivas: $\mathrm{O}$ respeito, o combate à intolerância, à diversidade cultural e à cultura de paz. A partir destes sentidos que foram atribuídos como forma de contribuir na formação dos alunos, podemos dizer que esses são elementos de ciclos de diálogos inter-religiosos desse ensino. Compreendemos assim, nos discursos aqui produzidos a relação de identidades e diferenças que a temática Budismo no Ensino Religioso pode propiciar.

Uma vez que no contexto escolar inclusive diante da história do Ensino Religioso as relações de poder estabelecidas entre as "identidades hegemônicas" como (ocidentais, religiões cristãs etc.) muitas vezes são incorporadas através do seu currículo, legitimando assim, determinadas culturas e excluindo, segregando e silenciado as consideradas "minoritárias", inclusive quando diz respeito às questões do campo das religiões. Segundo Santomé (1998, p. 161), “as culturas ou vozes dos grupos sociais minoritários e/ou marginalizados que não dispõem de estruturas importantes de poder costumam ser silenciadas, quando não estereotipadas e deformadas, para anular suas possibilidades de reação". E o Ensino religioso enquanto componente curricular deve propiciar o diálogo, o respeito defronte a uma sociedade multicultural, portanto, é nesse contexto que se faz necessária uma abordagem mais fortalecida do Budismo no Ensino Religioso.

Passamos a elucubrar o Budismo como tema emergente a ser contemplado no 
currículo do Ensino Religioso de forma crítica, contextualizada e reflexiva, de forma que atenda os objetivos desse ensino, contribuindo para os professores buscar caminhos de suprir a lacuna no que diz respeito à formação inicial e continuada. Assim, precisam se reorganizar nas práticas e pensar estrategicamente como trabalhar e incluir o budismo de forma não prosélito. Partindo dessa premissa, buscamos no próximo tópico desse ensaio apresentar possíveis formas de como trabalhar o Budismo no Ensino Religioso de modo simples que facilite a compreensão do aluno sobre as manifestações religiosas nesse universo de tradições, símbolos, ritos, mitos, entre outros que envolvem o Budismo.

4. Abordagens metodológicas do Budismo nas práticas pedagógicas do Ensino Religioso

Diante das questões teóricas e analíticas que foram apresentadas nesse estudo, iremos aqui apresentar algumas possíveis abordagens metodológicas de propostas pedagógicas para trabalhar o Budismo no componente curricular Ensino Religioso. Vale salientar que, para poder trabalhar essa questão, o ideal seria que o professor dessa área de ensino seja um profissional licenciado em Ciência (as) da (s) Religião (ões), uma vez que entendemos que esse profissional é de suma importância para realização de um trabalho que saiba discutir em sala de aula a questão da diversidade religiosa, que contribua na formação crítica, que saiba se posicionar em um mundo de infinitas variações e diferenças.

Entretanto, sabemos que a realidade das práticas pedagógicas do Ensino Religioso é em suas maiorias confessionais e prosélitas, apesar das lutas históricas em prol ao combate dessas ações, ainda há rejeição e má interpretação dos professores acerca desse ensino. De acordo com Pauly (2004, p. 176), "Há necessidade distinguir entre a fé e a religião, ou seja, a crença na divindade não implica em conhecimento sobre ela". E essa distinção que os profissionais dessa área devem ter consciência e saber separar suas convicções religiosas de um conhecimento crítico acerca do fenômeno Religioso que é objeto de estudo do Ensino Religioso, é nessa conjuntura que elencamos o cuidado que o professor deve ter em não se apresentar como confessional e prosélito nas ações pedagógicas ao abordar o Budismo.

Assim, é importante que "as práticas formadoras que se pautem na diversidade contribuem nos encaminhamentos para uma concepção e percepção da humanidade que 
se percebe heterogênea" (OLIVEIRA e KOCH, 2012, p. 459). É nessa perspectiva que nos direcionamos que o diferente é o comum, pois este é um dos objetivos desse ensino em contemplar as diversidades religiosas culturais existentes no mundo, seja religiões ocidentais ou orientais. Por outro lado, o professor deve ser aberto ao diálogo e buscar formas de apresentar atividades capazes de levar o reconhecimento, o respeito e a valorização perante essa diversidade.

Diante disso, apresentamos a seguir, uma possível prática pedagógica de como o Budismo poderia ser trabalhado de uma forma simples, clara, crítica e sistemática, em uma perspectiva de conhecimento da história, cultura, de significados, de essência, de altruísmo, de afetividade e cultura de paz. Ressaltamos que não será feito aqui passo a passo de como cada professor deve ensinar, mas será um norteamento de elementos importantes do Budismo enquanto religião e/ou filosofia de vida para ser apresentado ao aluno. Desse modo, contribui para o professor de Ensino Religioso diante dos temas norteadores e dos objetivos a possibilidade de planejar e elaborar as aulas de forma mais clara, a partir dos pontos relevantes que aqui são abordados. No entanto, essa proposta não é algo fixo e imposto, mas apenas estimular e mostrar aos professores de Ensino Religioso que o Budismo é possível ser trabalhado de forma reflexiva e crítica. 


\section{ENSINO FUNDAMENTAL DE $1^{\circ}$ AO $5^{\circ}$ ANO}

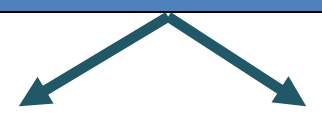

\begin{tabular}{|c|c|}
\hline TEMAS NORTEADORES & OBJETIVOS \\
\hline Budismo enquanto História & $\begin{array}{l}\text { - Apresentar a História do Budismo, como } \\
\text { o nascimento de Sidarta Gautama, e como } \\
\text { se expandiu o Budismo na questão de } \\
\text { território, territorialidade, etc. } \\
\text { - Desconstruir a imagem do Buda, uma vez } \\
\text { que ele é compreendido erroneamente nos } \\
\text { livros e em outros materiais didáticos que } \\
\text { são elaborados para crianças. E apresentar } \\
\text { a imagem real dele e desmistificar a ideia } \\
\text { de Buda como um Deus ou divindade. }\end{array}$ \\
\hline Budismo enquanto Tradição & $\begin{array}{l}\text { - Entender os princípios éticos no sentido } \\
\text { do reconhecimento que somos autores da } \\
\text { nossa própria vida na relação causa-efeito } \\
\text { e na forma particular de ver e sentir o } \\
\text { mundo. } \\
\text { - Apresentar e problematizar sobre os } \\
\text { símbolos sagrados, os ritos, os mitos, a } \\
\text { mística, que envolvem o Budismo, } \\
\text { principalmente falar dos significados para } \\
\text { essa religião acerca da Flor de Lótus, os } \\
\text { mantras, os significados das cores, entre } \\
\text { outros. }\end{array}$ \\
\hline Budismo enquanto Identidade & $\begin{array}{l}\text { - Possibilitar a percepção do "eu" } \\
\text { consciente dos pensamentos e impulsos e } \\
\text { emoções que surgem no nosso próprio ser. } \\
\text { - Construir a identificação da importância } \\
\text { do respeito com "si" e com o "outro". }\end{array}$ \\
\hline Budismo enquanto Valores & $\begin{array}{l}\text { - Contribuir para a análise da forma de } \\
\text { como vemos o mundo e como interagimos } \\
\text { com as pessoas e com o meio ambiente. } \\
\text { - Possibilitar a reflexão de como } \\
\text { contribuímos para o cuidado de si, com os } \\
\text { demais seres vivos e com o meio ambiente. }\end{array}$ \\
\hline
\end{tabular}

Quadro 02: Sistematização de Prática Pedagógica

Fonte: Quadro organizado pela autores. 
Refletir sobre as atividades a serem desenvolvidas com os alunos a partir dos temas e objetivos aqui propostos, é preciso ter a compreensão de que os conteúdos planejados nos primeiros anos do Ensino fundamental devem ser elaborados por meio de atividades lúdicas como: jogos, brincadeiras, imagens, músicas etc. De acordo com Almeida (1998, p. 31-32), as atividades lúdicas objetiva a "libertação das relações pessoais passivas, técnicas para relações reflexivas, criadoras, inteligentes, socializadoras [...] sem perder o caráter de prazer, de satisfação individual e modificador da sociedade". Nesse sentido, o professor de Ensino Religioso passar assumir a postura de despertar a curiosidade e a atenção acerca do Budismo. Para os últimos anos do Ensino Fundamental apresentamos as seguintes propostas:

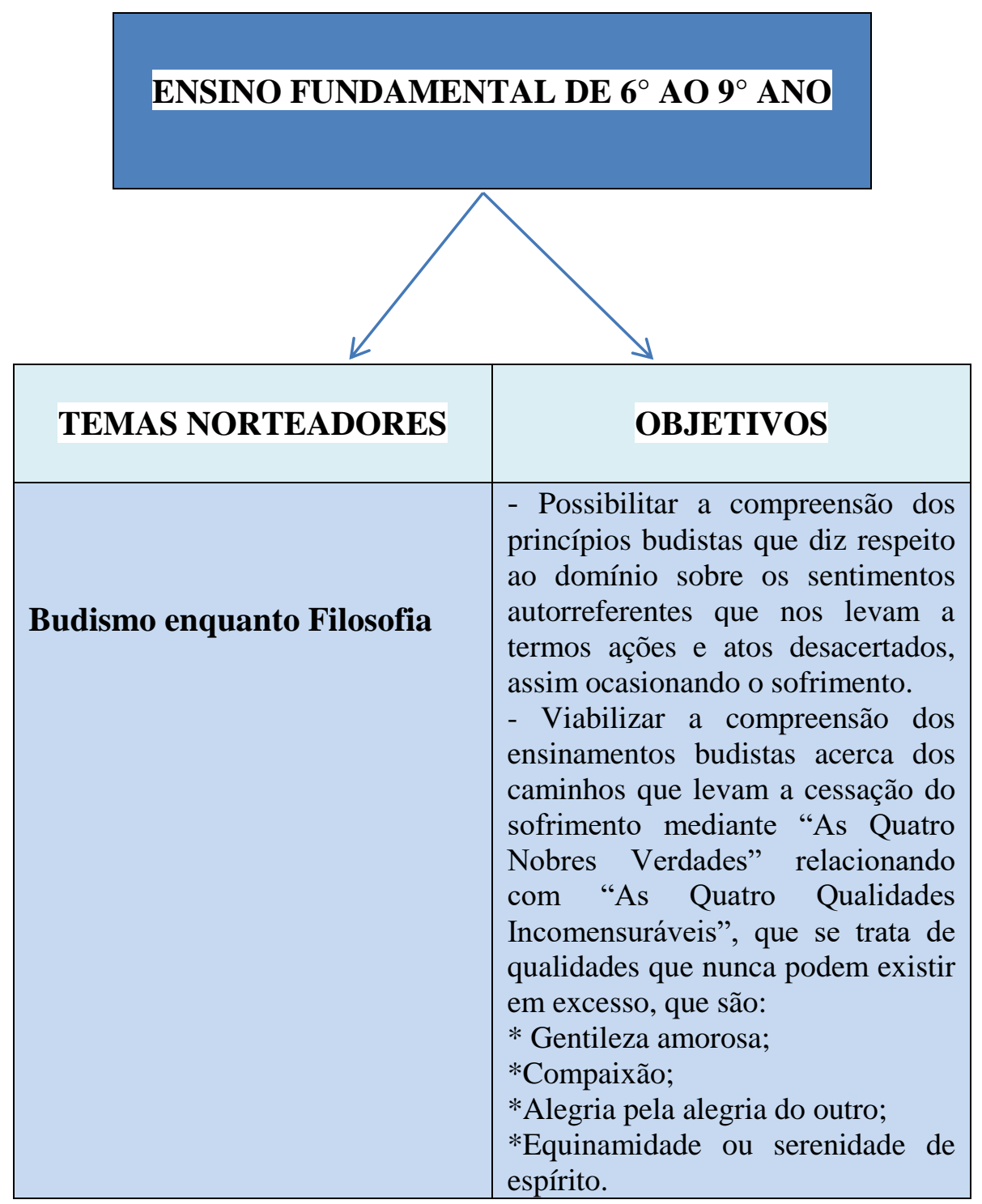




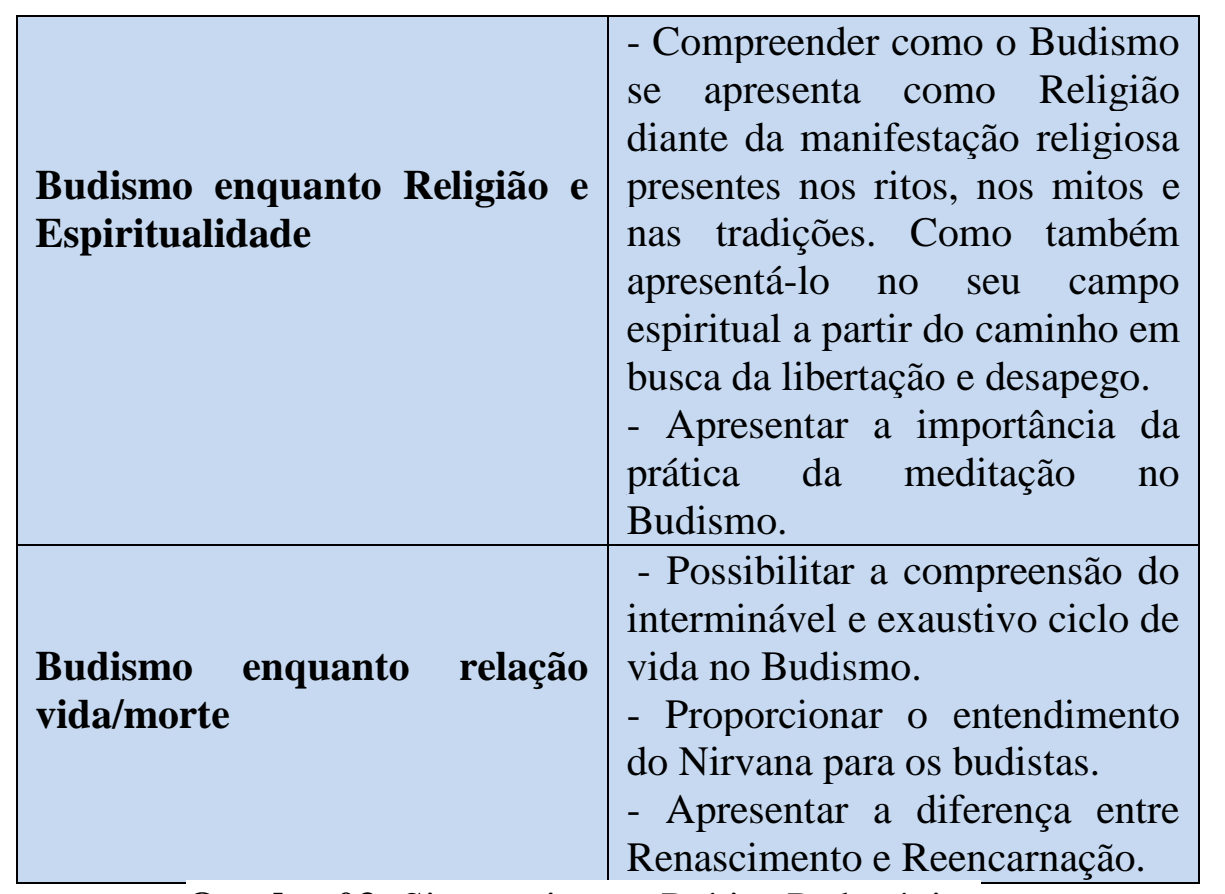

Quadro 03: Sistematização Prática Pedagógica

Fonte: Quadro organizado pelos autores.

Nessa segunda fase do Ensino fundamental propomos elementos que foram nomeados de temas norteadores mais aprofundados do universo budista, uma vez que a faixa etária desses alunos permite ter um entendimento mais reflexivo e crítico dessa religião, apresentando as particularidades dessa religião em uma perspectiva identitária exclusiva do Budismo. Assim, queremos destacar também que na Educação de Jovens e Adultos (EJA) esses mesmos temas e objetivos expostos para as duas fases do Ensino Fundamental podem ser trabalhados com esses alunos, contudo é preciso que as atividades sejam planejadas, desenvolvidas e dialogadas a partir da vivência que eles têm no mundo em que estão inseridos, respeitando assim, as suas experiências adquiridas ao longo da vida.

Vale ressaltar o quão é importante considerar o Budismo como uma tendência emergente a ser abordado nas práticas curriculares do Ensino Religioso, tendo em vista que um dos fatores principais na abordagem dos estudos budistas enquanto cultura de paz. Não colocamos esse tema norteador nos quadros supracitados por entendermos que ele deverá fazer interlocuções com todas as etapas do componente curricular Ensino Religioso. Pois essa temática, assim como o Ensino Religioso tem como objetivo principal reverberar a cultura de paz. Para isso, conforme Bomfim (2012, p.228), “é 
preciso estimular e estudar valores, atitudes e comportamentos (a amizade sincera, a liberdade, a tolerância, a justiça, a solidariedade; repudiar todas as formas de violência, estimular a atitude da escuta do si e da/o outra/o, respeitar os outros seres vivos [...])", Partindo-se dessas concepções diante dos ensinamentos budistas passa a fomentar a construção da cultura de paz de forma analítica no Ensino Religioso.

\section{Considerações finais}

Diante do exposto, podemos levar em consideração que os estudos sobre o Budismo no Ensino Religioso ainda é um campo pouco explorado. Isso ocorre devido à falta de conhecimento por parte da formação inicial e continuada dos professores dessa área por não terem sido suficientes para ampliar as discussões e reinterpretar as crenças e as práticas budistas, entende-se que: O que não é conhecido não é aprofundado.

Construímos nesse estudo uma abordagem reflexiva, crítica e ações de como poderíamos pensar na construção de práticas curriculares no que diz respeito aos Projetos Políticos Pedagógicos, aos planejamentos de planos de aula e as ações pedagógicas, e ir além dos livros didáticos de como contribuir na formação dos discentes desse ensino de forma simples, evidente, não prosélito e não confessional.

Essas dificuldades apresentadas pelos professores de Ensino Religioso ao falar do Budismo em sala de aula se fortaleceram a partir das respostas analisadas diante do questionário que foi aplicado, apesar de ter sido realizado com três professores podemos perceber as congruências entre eles. Assim fortalecendo a ideia de que a falta de informação é que leva a pouca e/ou a falta de exposição dessa religião ou filosofia de vida (como querem chamar) nas aulas de Ensino Religioso, fazendo assim com que essa temática seja segregada ou abordada de forma indevida.

Essas questões motivaram a fazer uma proposta viável de possibilidades a partir de temas norteadores e objetivos para ampliar a visão e estimular os professores desse ensino em buscar conhecer mais sobre o Budismo, assim tornando uma mão de via dupla, onde os professores ao pensar e planejar as aulas também estarão aprendendo, (re) construindo e ampliando conceitos diante do universo de ensinamentos budistas que podem contribuir na formação dos alunos de forma significativa, no sentido da valorização do respeito diante da diversidade cultural religiosa.

Portanto, acreditamos que a nossa proposta de construção de práticas curriculares acerca do Budismo no Ensino Religioso é um caminho viável podendo ser 
trabalhado de forma que determinados dogmas devem ser (re) pensados, (des) construídos e ampliados sobre o Budismo em sua forma prática. Essas abordagens dão sentidos e contemplam as religiões que são pouco abordadas, podendo assim ser (re) formulada e aplicada nas demais manifestações religiosas, de forma que todas sejam incorporadas nas práticas curriculares do Ensino Religioso.

\section{Referências}

ALMEIDA, Paulo. Educação Lúdica: Técnicas e Jogos Pedagógicos. Edições Loyola. São Paulo. SP, 1998.

AMORIM, Roseane Maria de. NETO, José Batista. Práticas Curriculares Cotidianas: os fios e tramas da educação das relações etnicorraciais em escola da rede municipal do recife. Espaço do Currículo, v.5, n.1, p. 331-345, Jun./ Dez., 2012.

ANDRADE, Solange Ramos de. História das Religiões e Religiosidades: uma breve introdução. In: FILHO, Eduardo Meinberg de Albuquerque Maranhão. (org). (Re) Conhecendo o Sagrado: reflexões teórico-metodológica dos estudos de religiões e religiosidade. São Paulo: Fonte Editorial, 2013, p. 11-32.

BHIKKHU VEM, Buddhadasa. Pontos Essenciais dos Ensinamentos Budhistas. In: SASAKI, Ricardo.(org). Jóias Raras: do ensinamento budhista. Belo Horizonte: Nalanda, 2013.

BOMFIM, Maria do Carmo Alves do. CULTURA DE PAZ NA ESCOLA: É POSSÍVEL? In: ANDRADE, Fernanado. (org). Escola: faces da violência, faces da paz. João Pessoa, Editora Universitária da UFPB, 2012, p. 211-230.

DHAMMASAMI VEM, Khammai. As Quatro Nobres Verdades. In: SASAKI, Ricardo. (org). Jóias Raras: do ensinamento budhista. Belo Horizonte: Nalanda, 2013, p. 51- 60.

MACEDO, Elizabeth. Currículo como espaço Currículo como espaço-tempo de fronteira cultural. Revista Brasileira de Educação, v. 11 n. 32, p. 285- 296, maio./ago., 2006.

MORESI, Eduardo. Metodologia da Pesquisa. Universidade Católica de Brasília -UCB, 2003.

NASSER, Maria Cecília de Queirós Cabrera. Contando histórias em sala de aula: um dica para o Ensino Religioso. In: KRONBAUER, Selenir Corrêa Gonçalves. SOARES, Afonso Maria Ligorio. (Org). Educação e Religião: múltiplos olhares sobre o ensino religioso. São Paulo, Paulinas, 2013, p. 15-34.

OLIVEIRA, Irene Dias de. Religião e as teias do multiculturalismo. São Paulo, Fonte Editorial, 2015.

OLIVEIRA, Lilian Blanck de. KOCH, Simone Riske. Diversidade Cultural Religiosa e formação de docentes de ensino religioso na FURB/SC: tecendo cartografias. In: Numem: revista de estudos e pesquisa da religião. (org) Programa de Pós-graduação em Ciência da Religião da Universidade Federal de Juiz de Fora, v. 15, n.2, Juiz de Fora: Editora UFJF, 2012, p. 455-480. 
OLIVEIRA. Lilian Blanck de. JUNQUEIRA. Sérgio Rogério Azevedo. ALVES. Luiz Alberto Sousa. KEIM. Ernesto Jacob. Ensino Religioso: no Ensino Fundamental. 1 ed. São Paulo: Cortez, 2007.

PAULY, Evaldo Luis. O dilema epistemológico do ensino religioso. Revista Brasileira de Educação, 27 Rio de Janeiro Sept./Oct./Nov./Dec. 2004.

RINPOCHE, Chagdud Tulku. O caminho budista: uma breve introdução. Três Coroas: Makara, 2012.

SANTOMÉ, Jurjo Torres. Globalização e interdisciplinaridade: currículo integrado. Porto Alegre: Artmed, 1998.

SILVA, Georges da. HOMENKO, Rita. BUDISMO: psicologia do autoconhecimento. São Paulo, Editora Pensamento, 1998.

SILVA, Tomaz Tadeu da. Documentos de identidade. Belo Horizonte: Autêntica, 2012.

SMITH. Wilfred Cantwell. O sentido e o fim da religião. Tradução de Korndörfer, Geraldo. São Leopoldo, Sinodal, 2006. 